\title{
Impression management within the Zulu culture: Exploring tactics in the work context
}

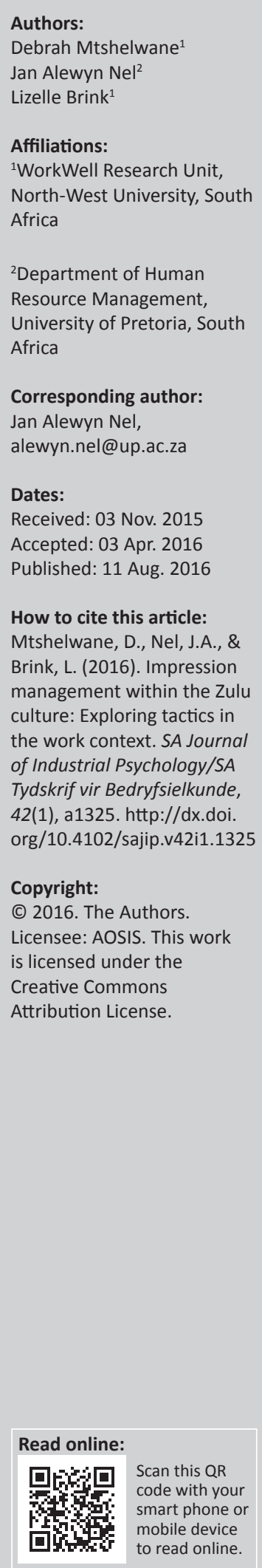

Authors:

Affiliations: North-West University, South

${ }^{2}$ Department of Human Resource Management, University of Pretoria, South

Corresponding author: Jan Alewyn $\mathrm{Nel}$

Dates:

Accepted: 03 Apr. 2016

How to cite this article: Mtshelwane, D., Nel, J.A., \& Brink, L. (2016). Impression management within the Zulu culture: Exploring tactics in Tydskrif vir Bedryfsielkunde, 42(1), a1325. http://dx.doi.

Copyright:

(C) 2016. The Authors. Licensee: AOSIS. This work is licensed under the Creative Commons Attribution License.
Orientation: Impression management tactics are utilised differently by people depending on the situation and the others around them.

Research purpose: The purpose of the study was to identify the impression management tactics Zulu people display when they want to impress people in a work context.

Motivation for this study: Organisations are competing for talented employees and people who contribute to the return on investment for the organisation. Individuals display impression tactics to influence the perceptions of others in the workplace, especially pertaining to performance appraisals and promotional opportunities.

Research approach, design and method: The social constructivism paradigm was employed in conducting this study, following a phenomenological approach. The research sample consisted of 30 Zulu-speaking individuals from various organisations who were interviewed through semi-structured interviews. The researcher used thematic analysis to analyse the data.

Main findings: The main findings in this study included impression management tactics that are used by Zulu people when attempting to impress people in the work context. The findings were divided into different categories (colleagues and supervisor). Conscientiousness, interpersonal amiability, openness and relational action are the themes that were reported as the most common impression management features people display at their workplace with colleagues. Themes that were reported when impressing a supervisor include conscientiousness, integrity, relational action and skilfulness.

Practical/managerial implications: This study provides organisations with knowledge on the impression management tactics utilised by isiZulu employees. The nature of this information enables management to not misinterpret the use of certain tactics and will lead to more understanding and resilience by organisations and colleagues when working with isiZulu individuals.

Contribution/value-add: This study contributes to the body of knowledge concerning impression management tactics within the South African context. The findings of this study might assist management to invent tools that are effective to identify impression management tactics, not just in the Zulu culture but within numerous other cultures in the South African spectrum.

\section{Introduction}

The social identity theory states that individuals tend to categorise themselves into social groups, pertaining to aspects such as their workplace (organisations), culture, religion and/or gender (Hogg \& Terry, 2001; Jenkins, 2014; Trepte, 2006). Social identity is based on the premise that people exhibit certain characteristics they perceive as relevant to a certain group they belong to (Hogg \& Terry, 2001). Jenkins (2014) states further that individuals consist of different social identities, and therefore individuals adapt their identities to the environment they exist in. It seems that people choose whether to adhere to the rules put down by the specific social group they are functioning in. This statement emphasises Norris's (2011) notion that people follow diverse norms, values, roles and statuses, which are dependent on the individual's social group. Therefore, people ultimately modify and alter their behaviour when they perceive that the social situation requires them to do so. Depending on the context, the impression tactics people display may be sincere or deceptive, accurate or inaccurate, depending on the salience of the person's social and personal identity (Leary \& Allen, 2011; Sandal et al., 2014). Individuals are motivated by various elements, and these elements may guide them in what tactics they display (Jenkins, 2014). In any social interaction (with colleagues, friends, family, etc.), people have the tendency to control their images or identities in order to position themselves to achieve specific goals (Jeffrey, Webb \& Schulz, 2008). 
According to Leary and Kowalski (1990), these goals could be for materialistic, social, or psychological reasons.

\section{Research objectives}

From the above arguments, the researcher attempts to understand the behaviour, emotions and attitudes involved when impression tactics are displayed in a specific context, namely the work environment. The general objective is therefore to explore impression management and features that individuals exhibit with their colleagues and supervisors. The cultural group that was studied is the Zulu group. In the next section, the framework and perspective of impression management in the Zulu culture are discussed, and impression tactics are conceptualised. The background of the Zulu group is also discussed.

\section{Literature review}

\section{Social constructivism from an emic perspective}

In order to comprehend the topic of impression management within the study of social identity theory, it is important to discuss the framework and perspective relevant to reaching the overall objective of this study. This study is based on the social constructivism framework, since impression management is based on multiple realities (i.e. different social groups and personal motivations), which are influenced by the background of the individual (usually the culture) (Lui \& Chen, 2010). Patel, Gali, Patel and Parmer (2011) also stated that reality is a social construct of the individual's mind, and therefore individuals construct their own reality of the social environment they are functioning in. Based on this premise, it seems that people will choose certain impression tactics depending on their own individual assessment of the situation and what impression tactics are required.

Since the framework is evident, it is also important to understand the perspective of this study. As already stated in the last paragraph of the background, this study focused on the Zulu culture. Consequently, the perspectives of isiZulu participants are identified as well as the impression tactics they utilise. According to Pike (1954), the emic perspective is a culture-specific element that provides meaning to realities from a specific background. The researcher therefore utilised the emic perspective in her study of impression management tactics employed by the Zulu culture (Talti \& Özbilgin, 2008). In the following section, impression management is defined and discussed.

\section{Impression management}

Impression management is concerned with individuals' reality of the social situation they find themselves in (Patel et al., 2011). Impression management is an element of social desirability; it is defined by Schlenker (1980, as cited by Ellis, West, Ryan \& Deshon, 2002) as a conscious or unconscious effort to control the image that is perceived by others. Soran and Balkan (2013) state further that impression management is the inner motive that affects the view of how others see the individual. Impression management conveys favourable images to the public to encourage positive outcomes as a result (Howle, Jackson, Conroy \& Dimmock, 2014). However, impression management can also cultivate negative outcomes for the party that the image is being portrayed to and at times for the individual who is attempting to make the impression. As stated by Stark (2005), the suppressing of invaluable personal traits is referred to as recategorising, and expressing personal valuable traits is viewed as positive distinctiveness. If an individual over-exaggerates his or her positive image, some people might interpret the person's behaviour in the wrong way. It is possible to create and portray a certain image to people, but the reality is that it is not possible to control the response, feedback or ultimate thoughts and reactions of people.

Coget (2014) provides examples of some of the most general impression management tactics: the expression of enthusiasm, confidence and discipline; expressing individual excellence; and taking credit for accomplishments. Enthusiasm refers to a positive attitude towards one's work or life situations in general. Employers look for people who are exuberant with a great deal of enthusiasm when hiring individuals, because they believe such people will complete tasks on time (Bye et al., 2011). Confidence is the inner knowledge that whatever the outcome, it will be favourable; therefore the individual expresses confidence through the manner in which he or she behaves, while interacting with others or through the manner in which he or she does work (Coget, 2014).

Discipline is regarded as self-control over work or life situations, whereby the expression of individual excellence is the over-emphasis of accomplishments, knowledge or skills (Kacmar \& Carlson, 1999). When highlighting their own accomplishments, individuals have the desire to be acknowledged for what they have attained. According to Kacmar and Carlson (1999), the above-mentioned tactics are relevant to individuals who are self-focused. Self-focused individuals are persons who only highlight positive qualities about themselves and talk more about themselves (Kacmar \& Carlson, 1999). A person who is focused on others would typically draw on the good and positive aspects of other people by complementing, encouraging and supporting them (Bye et al., 2011). The above-mentioned tactics are just a few that people use to gain the approval of others, whether it is in a formal or informal setting or to achieve certain goals.

\section{Impression tactics in the work context}

Impression management tactics are developed from early childhood (Zook \& Russotti, 2012). From a very young age, everyone seeks acceptance and yearns to belong to or to be part of a group (Norris, 2011). As already discussed in the introduction, individuals function in different settings of life, which may include a person's work life or personal life. This means that people adapt to different groups of people on a daily basis, which could include family, friends or colleagues. In this section, more detail will be provided on the types of tactics that may be utilised when people interact in the work context. 
According to Leonardi and Treem (2012), in the workplace (formal setting), employees may identify a gap between desired and existing views about themselves and therefore feel motivated to alter or regulate the existing information about themselves to others (Leonardi \& Treem, 2012). Employees' desire acknowledgement and promotion from their supervisors on the work they do; however, only a few realise these desires (Cheng, Chiu \& Tzeng, 2012). It was found in the literature that employees display a sense of appreciation towards their supervisors' accomplishments and achievements, which, in turn, makes them seem more likeable to their supervisor (Gwal, 2015). For instance, to impress a supervisor, some individuals describe their talents and accomplishments to supervisors in order to appear competent and intelligent (Bolino, Klotz \& Daniels, 2014). This influences the way the supervisor rates the performance of the employee when conducting appraisals (Cheng et al., 2012).

Furthermore, there are gender differences in the tactics utilised by females and males in the workplace. Guadagno and Cialdini (2007) state that in the workplace females utilise the following impression tactics more than males: making excuses, apologies, hedges and using modesty. In contrast, males will embark on self-promotion tactics, acclaiming and favour-rendering. Singh, Kumra and Vinnicombe (2002) state that females display strategies that focus on building good, close relationships with their supervisors, whereas males ensure that they deliver the supervisor's objectives as well as their own. Further examples of impression management tactics utilised by females and males are provided below. According to Guadagno and Cialdini (2007), males apply masculine impression management tactics, whereas females apply more feminine tactics. It was found that males use more aggressive, defensive and intimidation tactics (being controlling over situations and acting independently) when impressing their supervisor, and females use more passive, mutual and compassionate tactics.

With regard to impressing colleagues, employees have the ability to use social cues to understand and effectively influence others and as a result to reach positive outcomes in the workplace (Singh et al., 2002). For example, if an individual wishes to be seen as friendly, compassionate or kind-hearted, he or she exhibits the behaviour best associated with these traits in order to enhance the quality of interpersonal relationships with colleagues at work (Howle et al., 2014). Lewis (2005) coined a term for such behaviour, namely self-promotion, which is when an individual draws too much attention to his or her accomplishments, in order to be perceived as capable by others. If an individual is favoured and liked by colleagues, he or she will have better work relations due to cohesion. It is said that people strive to present a good image to other employees, to be communal orientated, since their aim is to orient themselves with others by being connected, and they strive towards cultivating strong relations at work (Howle et al., 2014). Additionally, employees will use exemplification as an impression tactic; here, an individual would go above and beyond what is expected or necessary so that he or she can be perceived as committed and hardworking (Lewis, 2005).

An unintentional outcome would be when a person displays a supposedly favourable image, but the response from the people this image is displayed to results in an unfavourable outcome (Van de Mortel, 2008). In a previous study on impression management between employee and supervisor, it was found that using impression management tactics in a way that is discriminatory - in a negative manner - might result in the supervisor seeing the employee as incompetent and unprofessional, when in fact the aim was to create a favourable image (Bolino et al., 2014). Another example is when an employee overemphasises his or her achievements and accomplishments to colleagues (Harris, Kacmar, Zivnuska \& Shaw, 2007). This behaviour might be received in a negative light and colleagues might think the employee is trying to brag or thinks too much of himself or herself (Hunter, 2012). Other general tactics used by isiZulu employees in the workplace include displaying extreme competence and striving to complete tasks on time and deliver good and acceptable work (Masuku, 2005).

\section{Zulu culture}

The Zulu culture is centred on the preservation of life through the maintenance of healthy social relationships (Biyela, 2013). Individuals in the Zulu culture apply impression management tactics to some extent to maintain healthy relationships. The Zulu culture highlights some behaviour patterns and attitudes that people display to impress others. According to Ntuli (2012), in an informal setting or social environment of the Zulu culture, it is unacceptable for females to enter a room first or to walk in front of a male, whereas males walk in front of females as a sign of authority and leadership.

In Zulu society, bravery, fighting spirit and male power are associated with manliness, whereas vulnerability in males is associated with weakness (Hunter, 2012). Another example is that in the Zulu culture females who have larger bodies are favoured over thin or skinny females (Moyo, 2012). Different cultures perceive people's qualities differently. The Zulu value system does not allow persons to whisper; it is perceived as being rude (Norris, 2011). In Western culture, not making eye contact is seen a sign of disrespect, whereas for the Zulu culture you are expected to look away or have minimal eye contact when being addressed by your elders in the community or superiors in the workplace (Ntuli, 2012). In a workplace, when entering a room, Zulu individuals greet males first before greeting the females in the room. It is common to stand up for superiors as a sign of respect in Western culture, whereas in the Zulu culture standing is deemed disrespectful and sitting is considered correct and respectful (Norris, 2011; Ntuli, 2012).

In Western culture, when stepping into the office of a superior person, it is customary to wait to sit down until being offered a seat, whereas in the Zulu culture individuals sit down 
immediately when they step into the office without seeking permission (Moyo, 2012). For the Zulu individual, that means he or she is displaying respect by not remaining standing. Standing could also be interpreted as looking down at your superior, which is socially undesirable in the Zulu culture (Ntuli, 2012). Thus the above-mentioned patterns of behaviour that are deemed acceptable or not acceptable have an impact on the impression management tactics that individuals display. This article explores the impression management tactics that are prevalent in the Zulu culture, within formal and informal settings.

\section{Research design}

The research design consists of the research approach, research strategy and research method.

\section{Research approach}

A qualitative research design was employed in conducting this study following a phenomenological approach. Phenomenology is an approach utilised in qualitative research that seeks to understand people's lived experiences and their intentions within their 'life world' (Grabtree \& Miller, 1999). The researcher steps in as an outsider to gather data objectively on the specific phenomenon being studied, which in this case is the Zulu culture. Bogdan and Bilken (2007) further state that the phenomenological approach aims to find the meaning of certain events and interactions of ordinary people in a particular situation. With this research, the researcher attempts to gather the meaning of certain tactics displayed by individuals in the Zulu culture in both formal and informal settings.

\section{Research strategy}

A case study strategy was utilised in this research study. Robson (2011) defines a case study as the selection of a specific individual, group or institution to be studied by collecting data through a range of data collection methods such as observations, documentary analysis or interviews. The Zulu cultural group serves as the case for this study. A further inclusion criterion utilised within the isiZulu group was that participants needed to be permanently employed within a company consisting of at least 50 employees. This method has numerous benefits, as the researcher is able to gather proper and truthful ideas about behaviour and an indepth description and analysis of this single case (the isiZulu group). It is also the best way to study a phenomenon (i.e. impression management) and one of the best ways to challenge existing theoretical assumptions (Robson, 2011).

\section{Research method}

The research method consists of the literature review, research setting, entrée and establishment of researcher roles, sampling, data collection methods, recording of data, data analysis and strategies employed to ensure quality data, reporting style and ethical considerations.

\section{Research setting}

The interviews took place in the provinces of Gauteng and KwaZulu-Natal in South Africa and the interviews were conducted at various organisations. The organisations included consulting organisations, financial institutions, the police force and defence force. The participants' workplaces were used to conduct interviews, and these specific venues included offices or boardrooms for the sole purpose of convenience and privacy. A 'do not disturb' sign was placed on the outside of the door during interviews to avoid interruptions and noise.

\section{Entrée and establishing researcher roles}

The authors were the project planners and data analysts. The first author was responsible for the data collection because she speaks the Zulu language. She was also responsible for capturing the data in Excel and conducting the initial translations into English. A language editor was recruited to inspect and modify the initial translations. All the authors analysed the data, while two independent researchers and a cultural expert were used to evaluate the initial themes, subthemes and responses.

\section{Sampling}

A combination of both purposive and quota non-probability sampling was utilised in this study. Ethnically Zulu individuals $(N=30)$ aged 18-65 were interviewed for this study. The interviews were conducted in isiZulu. Data collection continued until data saturation was reached. Participants needed to meet the following criteria for the research that was conducted: They had to (1) be ethnically Zulu, (2) be permanently employed in an organisation that employed more than 50 permanently employed individuals, (3) reside in KwaZulu-Natal or Gauteng, (4) differ according to age and gender and (5) be willing to participate in the research project.

The sample from this data consisted of 30 participants from various organisations in South Africa. Of the 30 participants, $63 \%$ were from Gauteng and 37\% were from KwaZulu-Natal; $43 \%$ were females and $57 \%$ were males. The majority of participants were between the ages of 41 and 50 (37\%), whereas $20 \%$ of participants were between the ages of 18 and 30 , and $26 \%$ were between 31 and 40 . Only $17 \%$ of participants were older than 51 years. The majority of participants (60\%) had training in higher education; 33\% had training in further education and $7 \%$ had training in general education.

\section{Data collection methods}

For this study, data were collected through the use of semistructured interviews. All the participants who formed part of this study were asked the following two questions:

- In order to impress colleagues from your work, what features are socially desirable?

- In order to impress your supervisor, what features are socially desirable? 
The questions that were posed to the research participants were all related to impression management in a work context. A trial run, better known as a pilot study, was done before the initial data collection took place, to ensure that the research questions were understood and made sense and to make sure the process was without errors. Five individuals who were ethnically Zulu were used for the pilot study and resided in Gauteng and KwaZulu-Natal.

\section{Recording of data}

A tape recorder was used to capture the data provided during the interviews. However, permission was requested from participants to make use of the tape recorder. The identities of participants remained anonymous; the data was collected and safeguarded and was not exposed to the public or accessible to anyone except the researcher. The data that were captured on the tape recorder were transcribed into an Excel sheet for future analysis.

\section{Data analysis}

Thematic analysis was utilised in this study. Fereday and Muir-Cochrane (2006) describe thematic analysis as a form of pattern identification with the data, where the emerging themes result in the categories for analysis. However, Braun and Clarke (2006) state that thematic analysis deals with identifying and reporting repetitive patterns (themes) within the data. The steps in thematic analysis are discussed below:

Phase 1: Get acquainted with the data: The research questions were based on impression management tactics in the work context. The authors read through the data and reviewed each interview in order to get a general idea of the data. The first step gave the authors a general idea of the data collected, once the researcher had immersed herself in the data. An accredited language editor assisted with the clarification of terms in the Zulu language.

Phase 2: Generating initial codes: The thematic analysis was conducted manually in an Excel program; the program helped with the analysis, reduction and interpretation of the data (Vogt, Gardner \& Haeffele, 2012). In this step, the researcher generated codes from the data that were collected. According to Braun and Clarke (2006), coding is about identifying a feature of data, whether it is latent or semantic content that appears interesting to the analyst. To be able to conduct further analyses, initial codes were predetermined, in which data were organised into meaningful groups (Braun \& Clark, 2006). Themes within each separate code were identified after analysis.

Phase 3: Searching for themes: In this phase, a long list of different codes was presented from the data that were collected. The codes in this phase were sorted to form themes. In this process repetitive codes or codes sharing semantic meaning were identified and clustered together to form unique themes. Co-coders (two independent researchers and an isiZulu cultural expert) assisted in this phase with the classification of themes and subthemes.
Phase 4: Reviewing themes: This phase deals with the refinement of themes, and therefore the researcher refined the themes that were developed from the previous phase. In this process, the co-coders and researcher discussed which themes did not correlate and which themes needed to be merged or separated. The researcher once again read through the data thoroughly to ensure that there was no duplication of themes and that the themes selected corresponded with the initially developed codes.

Phase 5: Defining and naming themes: During this stage, the researcher defined and further refined the themes that were presented in the analysis. In this phase, the researcher allocated meanings to the themes by making sure there was no overlap between the themes. The researcher allocated proper names to the themes and made sure they reflected the correct content of the data collected. Examples of themes that were identified under impression management tactics at home include the following: active guidance, conscientious, interpersonal amiability and relational action.

Phase 6: Producing the report: In this phase, the final writeup and report were produced by the researcher. This article focuses specifically on impression management tactics in the Zulu culture within informal and formal settings. The data in this article are reported in table format. Each code has its own theme, subtheme and a direct response is included for each subtheme in order for the reader to understand how the characteristic was formulated.

\section{Strategies employed to ensure quality data}

Semi-structured interviews were conducted to gather data. With the assistance of co-coders, data were analysed thoroughly to ensure quality and objectivity. Shenton (2003) proposed the various criteria that were originally initiated by Lincoln and Guba (1999). These constructs have been accepted by many people who conduct qualitative research. Following are the above-mentioned criteria.

Credibility: Credibility refers to internal validity, which aims to ensure that the study measures exactly what it intended to measure, and it enquires on the congruence of the findings with reality (Shenton, 2003). A phenomenological approach was followed, as well as a case study strategy. Additionally, a combined quota and purposive sampling procedure was employed in order to validate the generated findings.

Transferability: External validity refers to the degree to which the findings of one study can be generalised to other situations (Shenton, 2003). The data collected in this study and the resultant findings are only transferable to full-time employees who are ethnically Zulu. The emic perspective was utilised and assumptions and generalisations were made with regard to this specific group.

Conformability: This construct is concerned with objectivity, ensuring that the information captured is not in any manner influenced by the researcher, but instead that all the data 
gathered represent the truthful ideas and perceptions of participants (Shenton, 2003).

Dependability: Dependability addresses the issue of reliability, that if the study were to be conducted again within the same context, with the same group of people, it ought to produce the same results (Shenton, 2003). This means that if this study were to be done again using the Zulu group, the same methodology would need to be used again and the same results should also be reflected. However, in this study, a pilot study was first conducted before the actual research to ensure that the actual data were dependable.

\section{Ethical considerations}

Permission was granted by the affiliated higher education institutions to continue with the study, and the authorities and employees from various organisations also provided consent to conduct the research. Harm can be avoided when it comes to ethical issues in research by applying appropriate ethical principles and including them in the research. These principles include the following: voluntary participation, anonymity, confidentiality, consent and being fully informed about research objectives (De Bod, 2011). In this study, participants were provided with a consent form explaining the background and purpose of the study being conducted; it was also verbally communicated to participants before an interview commenced, or before they signed the consent form, thereby ensuring clarity on the purpose of the study and that there were no misunderstandings. The researchers did not misinform or deceive participants about the study being conducted. Individuals who took part in this study are anonymous and no personal information is revealed in any manner whatsoever. No person was forced to participate in this study. Participants in this study were able to withdraw if they chose to do so during the study. All participants were treated with respect and dignity.

\section{Reporting}

An Excel sheet was used to document the results. Thereafter, themes and subthemes were extracted from the interviews; direct quotations were then used to confirm the data. The interviews were conducted in isiZulu and then translated to English by the first author herself. The translations were checked by a language editor.

\section{Findings}

The different categories (codes), themes and subthemes were extracted from the interview responses, and direct quotations were used to confirm the results. The findings consist of two tables pertaining to the two interview questions, namely 1) impression management features an employee would display to impress colleagues and 2) impression management features an employee would display to impress a supervisor. A discussion of the relevant themes and subthemes follows.
Table 1 consists of the main themes and subthemes, with the broad meaning and the original response of every theme and subtheme. The themes and definitions are discussed below.

\section{Active guidance}

An individual who gives valuable advice to colleagues is seen as impressive.

\section{Conscientiousness}

A conscientious employee works hard, goes the extra mile and is deliberate with his or her work in good way. It describes an individual who is a go-getter, focused, hardworking, the kind of person that takes initiative, takes responsibility, and is also effective and efficient in his or her work. The employee also adheres to rules, works righteously and is always engaged in and punctual for work. There is a high level of commitment and dedication; such employees strive to meet expectations and to deliver the best work.

\section{External control}

This theme is demonstrated by a person who has the ability to take care of situations.

\section{Household chores}

Actions belonging to this theme include cooking traditional food for colleagues and inviting them for lunch or dinner.

\section{Integrity}

A person who is authentic, honest, trustworthy and reliable, with good ethical behaviour, and who is truthful, is reported as impressive.

\section{Interpersonal amiability}

A person with this quality displays a high level of respect towards colleagues, is compassionate toward others, and easily accepts and creates a happy atmosphere with and for others. Such employees are peacemakers, humble, kind, friendly and loving.

\section{Intrapersonal control}

This theme refers to individuals who are calm, patient, confident, do not gossip and are not judgemental or offensive towards others. Usually they take pride in important things and submit to others.

\section{Openness}

This quality refers to an individual who is adaptable, openminded and accepting of people.

\section{Relational action}

This behaviour is displayed by a team player, who always supports and provides assistance to others and is always 
TABLE 1: Impression management features used with colleagues.

\begin{tabular}{|c|c|c|}
\hline Theme & Subtheme & Response \\
\hline Active guidance & Advising & 'Give advice and say things that will make everything easy for your colleagues' \\
\hline \multirow[t]{28}{*}{ Conscientiousness } & Deliberate & 'Be deliberate, be courteous' \\
\hline & Extra-mile & 'Doing better in your work and show people that you can do more' \\
\hline & Focused & 'Stay focused and socialise with individuals' \\
\hline & Opportunistic & 'Take hold of opportunities' \\
\hline & Good employee & 'To be a good employee and calm' \\
\hline & Hard-working & 'Being humble, work hard' \\
\hline & Initiator & 'Take initiative and control of all learning opportunities' \\
\hline & Intelligence & 'Display how intelligent you are' \\
\hline & Meet expectations & 'Meet expectations' \\
\hline & Productivity & 'Punctuality and productivity' \\
\hline & Resourceful & 'Be industrious' \\
\hline & Status (overly educated) & 'Portray self as an being overly educated person' \\
\hline & Dedication & 'Follow up and be dedicated' \\
\hline & Accountable & 'Dependable and accountable' \\
\hline & Best work & 'Do your work to the best of your ability' \\
\hline & Commitment & 'Do things that are not even part of your job, be committed' \\
\hline & Critical of own work & 'Being the helping hand, being reliable, honest and critical of your work' \\
\hline & Dependable & 'Dependable and accountable' \\
\hline & Efficient & 'Doing better in your work and show people that you can do more' \\
\hline & Engaged & 'Be involved at work and be supportive' \\
\hline & Enthusiastic & 'Enthusiastic' \\
\hline & Following up (work) & 'Follow up on the work you have done' \\
\hline & Passionate (work) & 'Be the kind of person who loves their work with passion' \\
\hline & Professionalism & 'Professionalism' \\
\hline & Proud (language) & 'Being proud of your language' \\
\hline & Time management skills & 'Keep time, meet deadlines' \\
\hline & Righteous & 'Do the right things, adhere to all the requirements, if work starts at 08:00 be here before or at 08:00 and not later' \\
\hline & Rule conscious & 'Do the right things, adhere to all the requirements, if work starts at 08:00 be here before or at 08:00 and not later' \\
\hline External control & Control (situation) & 'Take control of certain situations' \\
\hline Household chores & Cooking (traditional food) & 'To cook traditional food for guests such as people you work with' \\
\hline \multirow[t]{6}{*}{ Integrity } & Authentic & 'Take interest in people, be genuine' \\
\hline & Ethical behaviour & 'Have good and strong work ethics' \\
\hline & Honest & 'Being the helping hand, being reliable, honest and critical of your work' \\
\hline & Reliable & 'Being the helping hand, being reliable, honest and critical of your work' \\
\hline & Trustworthy & 'Ukuthembeka: trustworthy' \\
\hline & Truthful & 'Be truthful to colleagues' \\
\hline \multirow[t]{15}{*}{ Interpersonal amiability } & Acceptance (colleagues) & 'Do not discriminate any of your employees' \\
\hline & Compassionate & 'Treat people as family' \\
\hline & Create happy atmosphere & 'Make sure that the people you work with are happy' \\
\hline & Friendliness & 'Friendliness' \\
\hline & Gentle & 'Be gentle' \\
\hline & Humble & 'Being humble, work hard' \\
\hline & Kindness & 'To be the kind of person that shares knowledge with others' \\
\hline & Loving & 'Respect love and be patient with your colleagues' \\
\hline & Peaceful environment & 'Make the work environment enjoyable' \\
\hline & Peacemaker & 'Find a way to disagree and not by fighting' \\
\hline & Relevance & 'To be relevant to my friends' \\
\hline & Respectful (colleagues) & 'Respect all the people you work with' \\
\hline & Respecting (other cultures) & 'Respecting different cultures' \\
\hline & Respecting (others) & 'Speak in a way that shows respect to your colleagues' \\
\hline & Respectful (regardless of age) & 'You have to respect the people you work with no matter how young or older you might be' \\
\hline \multirow[t]{3}{*}{ Intrapersonal control } & Calmness & 'Be calm and confident' \\
\hline & Confident & 'Be confident and outspoken' \\
\hline & No gossiping & 'Ukuhleba 'gossiping' akufuneki' \\
\hline
\end{tabular}


TABLE 1 (Continues...): Impression management features used with colleagues.

\begin{tabular}{|c|c|c|}
\hline Theme & Subtheme & Response \\
\hline \multirow[t]{4}{*}{ Intrapersonal control $\dagger$} & Not embarrassing (yourself) & 'Socialise with other colleagues, do not embarrass yourself' \\
\hline & Patient & 'Respect love and be patient with your colleagues' \\
\hline & Pride (uniform) & 'You must take pride in your uniform' \\
\hline & Submissive (even angry) & 'You do not answer or respond to colleagues if you been commanded to do something, no matter how angry you are \\
\hline \multirow[t]{4}{*}{ Openness } & Accepting (mistakes) & 'Accept mistakes and ask for forgiveness' \\
\hline & Acceptance & 'Accept people you work with for who there are without judgement' \\
\hline & Open minded & 'Ask for assistance, maintain open relationships, respect your colleague's opinions even if they are not right' \\
\hline & Open to learning & 'Being open to learning more' \\
\hline \multirow[t]{25}{*}{ Relational action } & Straight forward & 'Be open with people and being straight forward' \\
\hline & Assistance & 'Work as part of a team, help your colleagues and always be there to assist' \\
\hline & Be available (colleagues) & 'Be there for your colleagues when they need you' \\
\hline & Cohesion (stand together) & 'Stand together and being supportive' \\
\hline & Compliment & 'In my line of work you compliment and salute' \\
\hline & Forgive & 'Accept mistakes and ask for forgiveness' \\
\hline & Good relations & 'Ask for assistance, maintain open relationships, respect your colleague's opinions even if they not right' \\
\hline & Gratitude & 'Be grateful for the people who help you at work' \\
\hline & Greetings (colleagues) & 'To greet people you work with in the morning and say goodbye when you leave work' \\
\hline & Helpful & 'To be a good listener and being helpful' \\
\hline & Honouring & 'Being honourable and honest' \\
\hline & Know colleagues & 'Get to know people's names, do my job well and be adaptable' \\
\hline & Listening & 'Listen to the people who work with you' \\
\hline & Outspoken & $\begin{array}{l}\text { 'To create topics where people can talk and respond, since l'm working in the planning environment I will create } \\
\text { something where people need to respond to what I'm saying' }\end{array}$ \\
\hline & Polite & 'Be polite' \\
\hline & Praising & 'In my line of work you compliment and salute' \\
\hline & Presentable & 'Represent your directorate or division' \\
\hline & Protective & 'Ukuthetha nabantu (fighting for people)' \\
\hline & Share knowledge & 'To be the kind of person that shares knowledge with others' \\
\hline & Take interest & 'Take interest in people, be genuine' \\
\hline & Team player & 'Be a team player' \\
\hline & $\begin{array}{l}\text { Team player (complement each } \\
\text { other) }\end{array}$ & 'The ability to work together as a team or complement each other' \\
\hline & Team player (help colleagues) & 'Work as part of a team, help your colleagues and always be there to assist' \\
\hline & Understanding & 'To a person who shows understanding and respect' \\
\hline & Well-mannered & 'Have a good manner in which you speak to your colleagues' \\
\hline \multirow[t]{2}{*}{ Sociable } & $\begin{array}{l}\text { Socialise (cook and invite } \\
\text { colleagues for dinner) }\end{array}$ & 'Cook and invite your colleagues for dinner' \\
\hline & Socialise (colleagues) & 'Socialise with other colleagues, do not embarrass yourself' \\
\hline \multirow[t]{2}{*}{ Social skills } & Communication skills & 'Communicate effectively' \\
\hline & Good communication & 'Maintain good communication with your colleagues' \\
\hline \multirow[t]{2}{*}{ Soft-hearted } & Humility & 'Humility' \\
\hline & Avoid conflict and stress & 'Avoid stressing, confrontation' \\
\hline Task orientated & Avoid trivial issues & 'Avoid petty issues' \\
\hline Traditional & Traditional (attire) & 'Wearing your traditional Zulu clothing' \\
\hline
\end{tabular}

$\dagger$, Data continues from previoues page.

available for others. Such a person is straightforward, a good listener, well mannered and courteous. At the same time, this person has good relationships with others, shares knowledge easily and compliments, greets and honours other people.

\section{Sociable}

This description fits a person who is open to socialising with others by means of having gatherings or cooking for and inviting colleagues to his or her house.

\section{Social skills}

This theme indicates someone with good communication skills.

\section{Soft-hearted}

This type of person avoids unnecessary conflict and is humble.

\section{Task oriented}

This individual avoids trivial issues and focuses on the task at hand.

\section{Traditional}

This describes individuals who dress in traditional wear.

Table 2 consists of the main themes and subthemes with the broad meaning and the original response of every 
theme and subtheme. The themes and definitions are discussed below.

\section{Conscientiousness}

A conscientious person goes the extra mile in terms of work, has immense discipline and commitment, and works hard. The person is accountable and focuses on career development. Such individuals display cleanliness, diligence and good time management skills and are always punctual, present themselves well and provide quality work.

\section{Individualistic driven}

The kind of individual who is self-sufficient.

\section{Integrity}

Authenticity, honesty and good ethics in the workplace are the characteristics that would be displayed by a person who wanted to impress his or her supervisor. Showing reliability and trustworthiness in the workplace will most likely impress your supervisor.

\section{Interpersonal amiability}

When employees display respect and friendliness towards their supervisor, it impresses him or her.

\section{Interpersonal control}

A person of great confidence, positivity and consistency will impress supervisors. Being able to separate personal life from work life is an impressive feature.

\section{Openness}

Being inquisitive and open to learn more about the work, as well as being adaptable to different work situations, are good qualities that will impress supervisors.

\section{Relational action}

Acknowledging the supervisor's presence and being agreeable on work-related matters will impress the supervisor. Buying gifts for the supervisor's birthday or complementing him or her, as well as being helpful at work and a team player, are tactics that will impress one's supervisor. Additional impression management tactics include being well behaved, well-mannered and helpful to someone who needs assistance.

\section{Skilfulness}

It is believed that when employees display their skills or abilities and show their willingness to learn more, it is likely to impress their supervisor. Additional features that were reported on include the following: being a person who is an initiator, doing more and getting work in order, adding value to your work and being as effective and efficient as possible.

\section{Social skills}

A person who is very well spoken, a good communicator and observant is most likely to impress his or her supervisor.

\section{Discussion}

The general objective of this study was to explore impression management tactics that are prevalent in the Zulu culture within the work context. The two specific objectives of this study were (1) to investigate the features displayed by a person when impressing others in a formal setting (with colleagues) and (2) to investigate the features displayed by a person when impressing others in a formal setting (with a supervisor).

\section{Impression management features in a formal setting (with colleagues)}

Conscientiousness, interpersonal amiability, openness and relational action are the themes that were reported on the most when impressing colleagues. Conscientiousness refers to an employee who is focused, hardworking and who consistently takes the initiative to meet expectations and deadlines. This type of employee is impressive to other colleagues, because they display qualities such as professionalism, punctuality, work engagement, commitment and dedication. Employees who are engaged with their work and who go the extra mile are regarded as an asset to the organisation, because they are willing to do and give more (Aslan \& Akarçay, 2014). Masuku (2005) supports this statement as well by stating that Zulu individuals are easy to work with, since they are eager, hardworking and committed to their work.

A person who displays the theme interpersonal amiability when trying to impress colleagues will make sure that he or she is friendly, gentle, kind, loving and respectful towards his or her colleagues. These features are closely related to the indigenous concept of ubuntu, which acknowledges that a person is a person because of other people, and therefore the importance of being kind and welcoming towards people is also applicable to the workplace (Chaplin, 2006). To impress co-workers, an employee would make sure that he or she accepts them, shows compassion towards them and always creates a positive working environment, so that they enjoy working with him or her.

In order to impress colleagues, an employee would make sure to be open to them with regard to work, and therefore openness as a theme is regarded as a very important feature when trying to impress others. As found in the findings, openness is related to being receptive about collaborative work or ideas. People are willing to learn and adapt to different situations. Pertaining to this theme further, if people can easily communicate with a colleague, it makes it easy to form relations with that person and especially with regard to working together (Sibisi, 1999). Being an open person draws people to want to work and feel comfortable with a colleague and also to believe they can receive anything from the colleague (Miki, 2009). 
TABLE 2: Impression management features used with supervisors.

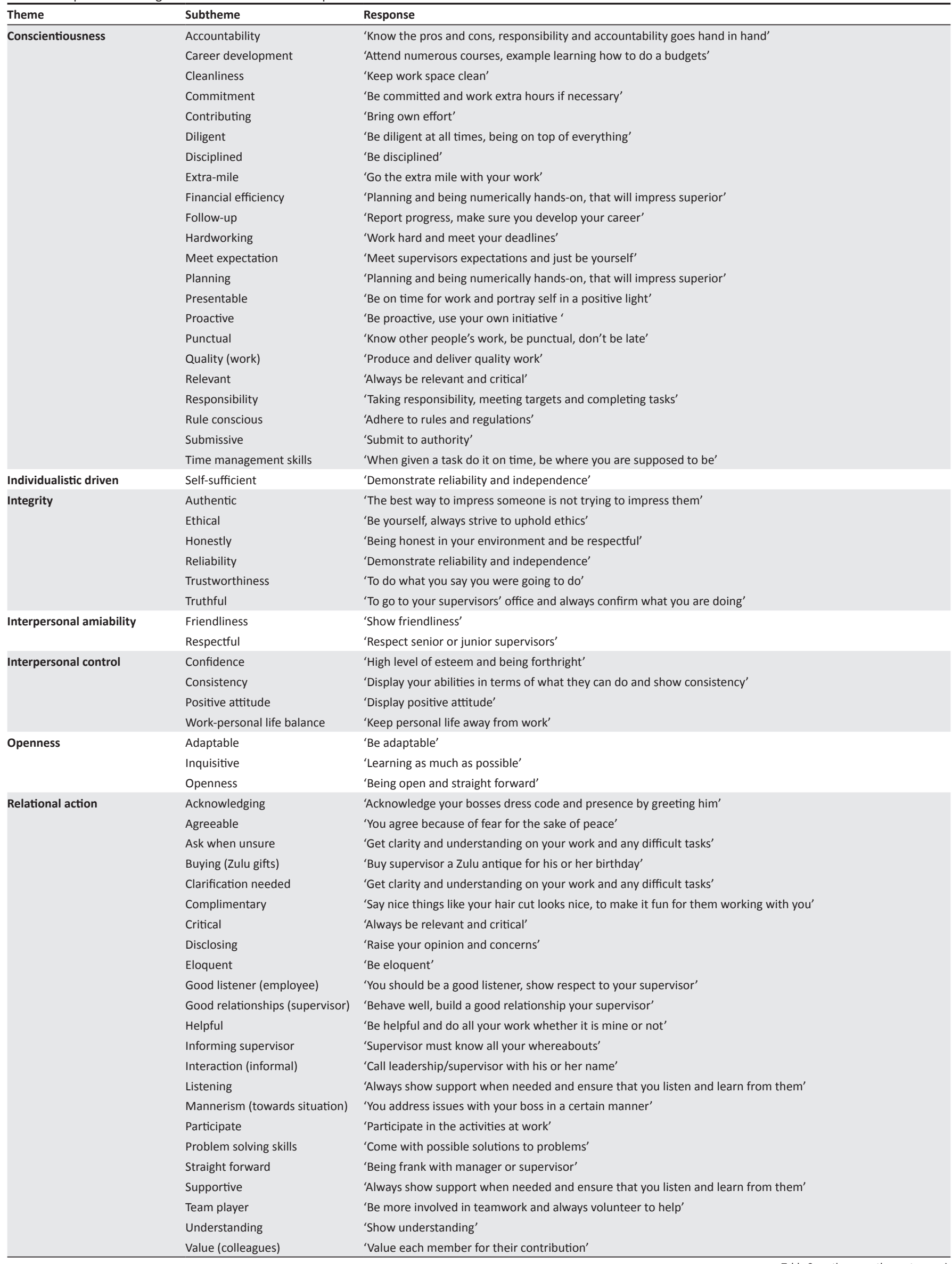


TABLE 2 (Continues...): Impression management features used with supervisors.

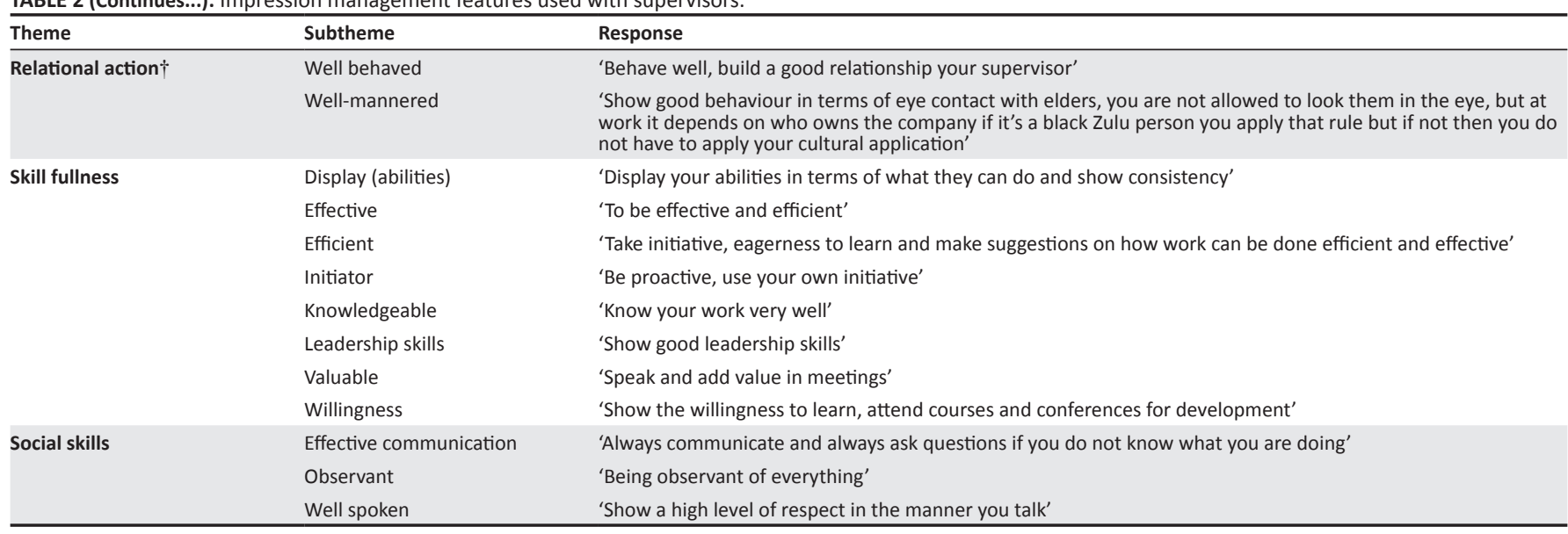

$\dagger$, Data continues from previoues page.

Relational action as a theme pertains to positive actions displayed in the workplace. Such a person would typically be available to help when needed and would make sure to greet and honour their colleagues. Employees use social cues to achieve a certain goal (Singh et al., 2002); therefore employees would share their knowledge and aim to be supportive and team players in order to maintain healthy workplace relationships with colleagues. The other side of the coin is true as well. According to Chaplin (2006), employees may utilise these tactics to gain or retain promotional relations with others in the workplace. Research findings reveal the same information with regard to impression tactics used by Zulu employees. According to Dube (2011), in the Zulu culture helpfulness, supportiveness, availability and sharing knowledge when needed are prominent actions that may spill over to the workplace. Guadagno and Cialdini (2007) also state that Zulu males use masculine tactics such as aggression, defensiveness and intimidation to get what they want and females display the total opposite attitudes to achieve similar goals, such as promotion or recognition. The female tactics include being passive, compassionate and being aware of the well-being of those with whom they work, whether it is a supervisor or colleague (Singh et al., 2002). Their behaviour would include smiling when speaking or being spoken to, as well as offering help and solutions to problems.

\section{Impression management features in a formal setting (with a supervisor)}

The themes that were reported on the most in the formal setting, when attempting to impress a supervisor, include conscientiousness, integrity, relational action and skilfulness. In a formal setting, an individual would display accountability, cleanliness, discipline and good quality work in order to be regarded as conscientious. Supervisors desire employees who are driven to work hard, are disciplined in their work and produce good quality work; this closely resembles the study conducted by Ingold, Kleinmann, Konig and Melchers (2015). However, Luvuno (2004) states that the abovementioned features are regarded primarily as values that individuals need to live by and are secondarily utilised by people as impression management tactics, depending on the circumstances.

Integrity as an important theme was reported as the tendency to display behaviour that is authentic, ethical, honest, trustworthy and truthful with a supervisor with regard to issues pertaining to work. Supervisors are seen on the same level as parents and elders in the Zulu culture (Sibisi, 1999). Parents should be shown respect and honour; it is necessary to adhere to their rules and stay true to the ethics of the culture (Sibisi, 1999). This corresponds to this study's findings pertaining to supervisors. It is clear that a supervisor is regarded as an elder in a formal setting (Sibisi, 1999), and therefore the same behaviour that an individual displays at home towards elders is the same behaviour that a Zulu individual (most likely) displays at work.

Relational action refers to displaying an attitude of being open to helping and assisting your supervisor when needed and also acknowledging your supervisor's presence. Being the type of employee who is a team player, is understanding, adds value, is a good listener and is well-mannered is said to impress a supervisor. Any organisation would regard an employee who added value with good teamwork skills and good professional behaviour as an asset to the organisation (O’Donnell \& Boyle, 2008). Leonardi and Treem (2012) provide the tactics used by employees to impress their supervisors, which include showing good teamwork skills, as well as individual capabilities, and being an individual who listens and delivers what is expected.

Displaying a high level of competence is believed to impress the people an individual works with, especially a supervisor. Skilfulness is also one of the themes that were identified as a feature when impressing a supervisor. It was reported that having good communication skills and being effective and efficient in carrying out work tasks were very important for the Zulu participants. It also entails having sound knowledge regarding the work. An individual with the desire to impress his or her supervisor would show extreme confidence when communicating his or her capabilities ( $\mathrm{O}^{\prime}$ Donnell \& Boyle, 2008). Being well spoken enables an individual to do 
business with people effectively and results in good client relationships and satisfaction (Hadebe, 2010). As much as impression management tactics are aimed at personal gain, it is evident that they also have a positive influence on organisational objectives. In a positive light, not only do employees excel, but they also have a positive impact on the growth of the organisation. In the next section, the implications of this study are discussed.

\section{Practical implications}

A positive image is important for individuals, especially in the workplace, since social acceptance stems from being received and drawn into a group and is a rewarding and pleasant feeling (De Wall \& Bushman, 2011). Every employee wants to maintain a high performance image in the workplace (Rosenfeld, Giacalone \& Riordan, 1995). It is vital for supervisors to understand impression management tactics and how employees utilise them within the work setting, so that whichever evaluations take place, the process remains objective and the results are reliable. It is also important to note the importance of distinguishing between impression tactics and employees who are genuinely working hard. Bye et al. (2011) state that it is important to be aware that when a positive image is created by an employee in the light of making others look bad, intentionally being negative towards other employees, such behaviour can result in the development of negative relations. Such tactics should be addressed by management, because they may create negative relations in the workplace. People from the Zulu culture, however, tend to display a sense of extreme hard work and excellence, although not necessarily trying to employ impression management tactics; in the Zulu culture, it is the nature of a Zulu person to work hard, to be self-reliant and independent (Xulu, 2002).

\section{Limitations and recommendations of the study}

The study is not without limitations. The sample size that was utilised in this study was only $N=30$. A larger sample could be used for future research and could include participants from across the different provinces, rather than just KwaZulu-Natal and Gauteng. For future research, it is recommended that the researcher include not only permanent employees, but also economically inactive participants (i.e. scholars, students, homemakers, retired employees). This would result in the possibility of generalising the results to a broader population. Different age groups can be included, as well as an equal number of people from rural and urban areas.

Coget (2014) suggests that organisations and supervisors educate corporate recruiters about how cultural values influence impression management tactics in job interviews. Supervisors could also host impression management workshops, where impression management is addressed by experts. In the same workshop, individuals in the organisations could do exercises on how they use impression management tactics. The results of cultures can be gathered into similar cultural groups and similar genders, so that they can compile a profile for each cultural group or different genders. The results of such an exercise could be reported and discussed in the workshop as feedback, so that not only would the supervisor have the information, but employees would also be informed on tactics employed by their colleagues. This feedback would provide the necessary information with regard to tactics utilised by men, women and the different cultures that exist in that specific organisation.

\section{Conclusion}

The overall purpose of this study was to explore the features that people in the Zulu culture will display to impress other people in a work context. Through this study, numerous impression management tactics that are prevalent in the Zulu culture were identified. It is evident that using impression management tactics is a personal choice; however, an individual's personal upbringing or culture can have an influence on the impression management tactics that individual displays. Impression management tactics are regarded as anything that highlights the positive qualities of a person (Kacmar \& Carlson, 1999). The following themes were identified in this study: (1) when attempting to impress colleagues, isiZulu individuals would display the following impression management tactics: conscientiousness, interpersonal amiability, openness and relational action; and (2) the themes that were identified when impressing a supervisor include conscientiousness, integrity, relational action and skilfulness.

\section{Acknowledgements Competing interests}

The authors declare that they have no financial or personal relationships that may have inappropriately influenced them in writing this article.

\section{Authors' contributions}

D.M. collected, captured and analysed the data and wrote the manuscript. J.A.N. and L.B. supervised the study; they assisted with the data analysis and provided feedback on the manuscript.

\section{References}

Aslan, S., \& Akarçay, D. (2014, June 16). The effects of impression management and organisational affective communication on citizenship performance. Paper presented at the Clute Institute's International Academic Conference, Munich, presented

Biyela, N.G. (2013). Colour metaphor in Zulu culture: Courtship communication in beads. American International Journal of Contemporary Research, 3(10), 37-41.

Bogdan, R.C., \& Bilken, S.K. (2007). Qualitative research for education: An introduction to theories and methods. (5th edn.). Boston, MA: Pearson Education Inc.

Bolino, M.C., Klotz, A.C., \& Daniels, D. (2014). The impact of impression management over time. Journal of Managerial Psychology, 29(1), 266-284. http://dx.doi. org/10.1108/JMP-10-2012-0290

Braun, V., \& Clark, V. (2006). Using thematic analysis in psychology. Qualitative Research in Psychology, 3(2), 77-101. http://dx.doi.org/10.1191/1478088706qp063oa 
Bye, H.H., Sandal, G.M., van de Vivjer, F.JR., Sam, D.L., Cakar, N.D., \& Franke, G.H. (2011). Personal values and intended self-presentation during job interviews: A cross- cultural comparison. The International Association of Applied Psychology, cross- cultural comparison. The International Association of Applied
60(1), 160-182. http://dx.doi.org/10.1111/j.1464-0597.2010.00432.x

Chaplin, K. (2006). The Ubuntu spirit in African communities. South African Ubuntu Foundation. Retrieved December 06 2014, from www.coe.int/t/dg4/ cultureheritage/culture/Cities/Publication/BookCoE20-Chaplin.pdf

Cheng, J.W., Chiu, W.L., \& Tzeng, G.H. (2012). Do impression tactics and/or supervisorsubordinators guanxi matter? Journal of Knowledge Based Systems, 4O(1), 123-133.

Coget, J. (2014). Do self-presentation tactics of job interviews vary across cultures? Journal of Academy of Management Perspectives, 28(4), 1-3. http://dx.doi. org/10.5465/amp.2015.0003

De Bod, A. (2011). Contemporary ethical challenges in industrial psychological: Testing in South Africa. Unpublished master's mini-dissertation, University of Johannesburg, Johannesburg, South Africa.

De Wall, C.N., \& Bushman, B.J. (2011). Social acceptance and rejection: The sweet and the bitter. Current Directions in Psychological Science, 20(4), 256-260. http://dx. doi.org/10.1177/0963721411417545

Dube, M.C. (2011). The tourism potential of Zululand north of the Tugela river with special reference to Zulu culture and history. Unpublished masters' dissertation, special reference to Zulu culture and history.
University of Zululand, Durban, South Africa.

Ellis, A.P.J., West, B.J., Ryan, A.M., \& DeShon, R.P. (2002). The use of impression management tactics in structured interviews: A function of question type. Journa of Applied Psychology, 87(1), 1200-1208. http://dx.doi.org/10.1037/00219010.87.6.1200

Fereday, J., \& Muir-Cochrane, E. (2006). Demonstrating rigor using thematic analysis: A hybrid approach of inductive and deductive coding and theme development. International Journal of Qualitative Methods, 5(1), 1-11.

Grabtree, B.F., \& Miller, W.L. (1999). Doing qualitative research. (2nd edn.). Newbury Park, CA: Sage Publications.

Guadagno, R.E., \& Cialdini, R.B. (2007). Persuade him by email, but see her in person: Online persuasion revisited. Computers in Human Behavior, 23, 999-1015. http:// dx.doi.org/10.1016/j.chb.2005.08.006

Gwal, R. (2015). Tactics of impression management: Relative success on workplace relationship. International Journal of Indian Psychology, 2(2), 37-44.

Hadebe, L. (2010). Zulu masculinity: Culture, faith and constitution in the South African context. Unpublished master's dissertation, University of KwaZulu-Natal, Durban, South Africa.

Harris, K.J., Kacmar, K.M., Zivnuska, S., \& Shaw, J.D. (2007). The impact of political skills on impression management effectiveness. Journal of Applied Psychology, 92(1), 278-285. http://dx.doi.org/10.1037/0021-9010.92.1.278

Hogg, M.A., \& Terry, D.J. (2001). Social identity theory and organisational processes. In M.A. Hogg \& D.J. Terry (Eds.), Social identity processes in organizational contexts (pp. 1-12). Ann Arbor, MI: Sheridan Books.

Howle, T.C., Jackson, B., Conroy, D.E., \& Dimmock, J.A. (2015). Winning friends and influencing people: Self-presentation motives in physical activity settings. International Review of Sport and Exercise Psychology, 8(1), 44-70. http://dx.doi. org/10.1080/1750984X.2014.991346

Hunter, C. (2012). Managing people in South Africa. Human resource management as competitive advantage. (2nd edn.). Durban, South Africa: Sherwood Books.

Ingold, P.V., Kleinmann, M., Konig, C.J., \& Melchers, K.G. (2015). Shall we continue or stop disapproving of self-presentation? Evidence on impression management and faking in selection context and their relation to job performance. European Journal of Work and Organisational Psychology, 24(3), 420-432. http://dx.doi.org /10.1080/1359432X.2014.915215

Jeffrey, S., Webb, A., \& Schulz, A. (2008, August 28). The use of set goals as an impression management tactic: Antecedents and consequences. Presented at the
Academy of Management Meeting, Anaheim, California, United States of Academy

Jenkins, R. (2014). Social identity theory. (4th edn.). New York: Routledge.

Kacmar, K.M., \& Carlson, D.S. (1999). Effectiveness of impression management tactics across human resource situations. Journal of Applied Psychology, 29(6), 1293-1311.

Leary, M.R., \& Allen, A.B. (2011). Personality and persona: Personality processes in self-presentation. Journal of Personality, 79(6), 1191-1281.

Leary, M.R., \& Kowalski, R.M. (1990). Impression management: A literature review and two-component model. Journal of Psychological Bulletin, 107(1), 34-47.

Leonardi, P.M., \& Treem, J.W. (2012). Knowledge management technology as a stage of strategic self-presentation: Implications for knowledge sharing in organisations. Journal of Information and Organisation, 22(1), 37-59. http://dx.doi.org/ 10.1016/j.infoandorg.2011.10.003
Lewis, A.M. (2005). Self-determination and the use of self-presentation strategies. The Journal of Social Psychology, 145(4), 469-489. http://dx.doi.org/10.3200/ SOCP.145.4.469-490

Lincoln, Y., \& Guba, E. (1999). Establishing trustworthiness. In A. Bryman \& R.G. Burgess (Eds.), Qualitative research (pp. 397-444). London, England: Sage.

Lui, C., \& Chen, I.C. (2010). Evolution of constructivism. Journal of Contemporary Issues in Education Research, 3(4), 63-66. http://dx.doi.org/10.19030/cier v3i4.199

Luvono, M.D. (2004). The status of women language use with particular reference to Isizulu (Unpublished master's dissertation). University of Zululand, Durban, South Africa.

Masuku, N. (2005). Perceived oppression of women in Zulu folklore: A feminist critique. Unpublished doctoral thesis, University of South Africa, Pretoria, South Africa.

Miki, N. (2009). Gift giving anxieties as a function of recipient characteristics. Unpublished master's degree, University of Wisconsin-Stout, Madison, WI.

Moyo, L. (2012). Participation citizenship and pirate radio as empowerment: The case of radio dialogue in Zimbabwe. International Journal of Communication, 6(1), 484-500.

Norris, A.R. (2011). Impression management. Considering, cultural, social and spiritual factors. Student Pulse, 3(7), 1-4.

Ntuli, C.D. (2012). Intercultural misunderstanding in South Africa: An analysis of nonverbal communication behaviour in context. Unpublished master's dissertation, University of South Africa, Pretoria, South Africa.

O'Donnell, O., \& Boyle, R. (2008). Understanding and managing organisationa culture. Dublin, Ireland: Institution of Public Management Research.

Patel, C.J., Gali, V.S., Patel, D.V., \& Parmar, R.D. (2011). The effects of information and communication technologies (ICTs) on higher education: From objectivism to social constructivism. International Journal of Vocational and Technical Education $3(5), 113-120$

Pike, K.L. (1954). The language in relation to a unified theory of the structure of human behaviour. (1st edn.). Glendale, CA: Summer Institute of Linguistic.

Robson, C. (2011). Real world research: A resource for uses of social research methods in applied settings. (3rd edn.). London, England: John Wiley and Sons.

Rosenfeld, P.R., Giacalone, R.A., \& Riordan, C.A. (1995). Impression management in organisations: Theory, measurement and practice. New York: Routledge.

Sandal, G.M., van de Vivjer, F., Bye, H.H., Amponsah, S.M., Cakar, N., Franke., G.H., \& Sun, T.L. (2014). Intended self-presentation tactics in job interviews: A 10 country study. Journal of Cross Cultural Psychology, 45(1), 939-458. http://dx.doi. org/10.1177/0022022114532353

Shenton, A.K. (2003). Strategies for trustworthiness in qualitative research projects. Education for Information, 22(1), 63-65.

Sibisi, I., S.Z. (1999). The influence of indigenous African education in attitudes towards authority with special reference to the Zulus. Unpublished master's dissertation, University of Zululand, Durban, South Africa.

Singh, V., Kumra, S., \& Vinnicombe, S. (2002). Gender and impression management: Playing the promotion game. Journal of Business Ethics, 37(1), 77-89. http://dx. doi.org/10.1023/A:1014782118902

Soran, S., \& Balkan, M.O. (2013). The effects of impression management tactics on emotional impressions: Research on banking sector. Journal of Strategic Management, 13(1), 154-165. http://dx.doi.org/10.20460/jgsm.2013715681

Stark, M. (2005). Creating a positive professional image. Research \& ideas: An interview session. Retrieved June 20 2014, from http://hbswk.hbs.edu/ item/4860.html

Talti, A., \& Özbilgin, M.F. (2008). An emic approach to intersectional study of diversity at work: A Bourdieuan farming. International Journal of Management, 14(10), $180-200$.

Trepte, S. (2006). Social identity. In B. Jennings \& P. Vorderer (Eds.), Psychology of entertainment (pp. 255-271). New York: Routledge.

Van de Mortel, T.F. (2008). Faking it: Social desirability response bias in self-reporting research. Australian Journal of Advanced Nursing, 24(4), 40-48.

Vogt, W., Gardner, D.C., \& Haeffele, L.M. (2012). When to use what research design New York: The Guilford Press.

Xulu, C.B.S. (2002). Colour coding and its meaning in the Zulu woman's beadwork: A study of Zulu woman's beadwork in fashion design and decorating. Unpublished masters' dissertation, University of KwaZulu-Natal, Durban, South Africa.

Zook, J.M., \& Russotti, J.M. (2012). Academic self-presentation strategies and popularity in middle schoos Journal of Early Adolescence, 33(6), 765-785. http:// dx.doi.org/10.1177/0272431612467229 